\title{
Survival of Vibrio cholerae in industrially polluted water, with particular reference to iron concentrations
}

\author{
Mrudula Patel ${ }^{*}$, Margaretha Isaäcson and Hendrik J Koornhof \\ Department of Clinical Microbiology and Infectious Diseases, National Health Laboratory Service and University of the Witwatersrand, \\ Faculty of Health Sciences, Private Bag 3, Wits 2050, South Africa
}

\begin{abstract}
High levels of iron are often found in surface waters due to the discharge of iron-containing industrial effluents. The effect of iron as well as $\mathrm{pH}$ on the survival of Vibrio cholerae (non-O1, El Tor and classical strains) in water samples from 12 points, where selected industrial effluents were discharged into rivers, was studied. All three $V$. cholerae strains survived longest during spring. $V$. cholerae non-O1 survived significantly longer than El Tor and classical strains. At $\mathrm{pH} 8.0$, the survival of $V$. cholerae increased with increase in iron concentration $(1 \mathrm{to} 10 \mathrm{mg} / \ell)$ of polluted water. At lower than $\mathrm{pH} 8.0$, the effect of iron was not significant. In polluted water, at $\mathrm{pH} 8.0$, the presence of iron resulted in prolonged $V$. cholerae survival at lower concentrations than those required for survival in distilled water. We suggest that chemical contamination of water may be one of the important factors instrumental in the subsequent ability of $V$. cholerae to persist, multiply and survive in the aquatic environment.
\end{abstract}

Keywords: Vibrio, Vibrio cholerae, $V$. cholerae, iron, $\mathrm{pH}$, industrial effluent

\section{Introduction}

Industrial pollution of surface and groundwater may pose a variety of health threats, particularly in heavily industrialised areas where the quality of raw water tends to deteriorate. The pollutants are mainly inorganic and organic chemical compounds depending on the type of industries around the water source. It is important to understand the impact of specific pollutants of industrial effluents on plants, animals, humans and micro-organisms. This study has researched only the effect of iron and $\mathrm{pH}$ on cholera-causing microorganisms.

High levels of iron may be found in surface waters as a result of the discharge of certain industrial effluents. Iron often enters streams in a soluble form but rapidly becomes insoluble. In surface waters, iron commonly occurs in two oxidation states, ferrous $\left(\mathrm{Fe}^{2+}\right)$ and ferric $\left(\mathrm{Fe}^{3+}\right)$. The redox potential and $\mathrm{pH}$ of the aquatic environment play major roles in determining the behaviour of this metal in water. In the presence of oxygen, ferrous iron is oxidised to the ferric state, which precipitates. Iron in surface waters is therefore usually found as a colloid suspension of ferric hydroxide, which may settle out and harden to a cement-like material. However, in the presence of oxygen and $\mathrm{pH}$ values of less than 3.0, the soluble ferric state of iron is dominant, while under neutral and alkaline conditions, ferric hydroxide and ferric oxide complexes are formed. In reducing conditions, ferrous iron may persist and occur in high concentrations, provided that sulphides and carbonates are absent (Ford and Dana, 1963; DWAF, 1996).

In a previous study on Vibrio cholerae survival in distilled water with $\mathrm{pH}$ values between 7 and 9 without added nutrients, except for varying quantities of ferric oxide, increase of the latter was associated with enhanced survival (Patel and Isaäcson, 1995).

\footnotetext{
* To whom all correspondence should be addressed.

I +2711717 2113; fax: +2711 7172027 ;

e-mail: Patelms@dentistry.wits.ac.za

Received 27 Jaruary 2003; accepted in revised form 1 October 2003.
}

At $\mathrm{pH} 7$, survival enhancement was optimal at iron levels ranging from $0.1 \mathrm{~g} / \ell$ to $1.0 \mathrm{~g} / \ell$, whilst at $\mathrm{pH} 9$ it was optimal at iron levels ranging between $0.01 \mathrm{~g} / \ell$ and $0.1 \mathrm{~g} / \ell$. These findings stimulated the current investigation in which industrially polluted waters from the heavily industrialized Gauteng province in South Africa were used for further study. These waters which contained a wide range of iron and $\mathrm{pH}$ levels, were collected and inoculated with $V$. cholerae, the survival of which was then monitored over a period of time.

\section{Methods and materials}

\section{Water sampling sites}

To monitor pollution, Rand Water, Vereeniging, a major South African water supply company, routinely inspects the catchment areas from which it draws raw water. Regular samples of river water are subjected to chemical, bacteriological and biological analyses. The samples used in this study were collected from these same catchment areas.

Twelve water sampling points where industrial effluents are discharged into rivers or streams were selected to represent a broad range of iron concentrations. These points had shown fairly consistent iron levels during the previous 10 years (Rand Water Board, 1987).

\section{Collection and pre-inoculation testing of water samples}

Following a study conducted by ourselves in 1989, which illustrated the effect of iron on survival of $V$. cholerae in distilled water (Patel and Isaäcson, 1995), it was decided to collect water samples containing industrial effluent in order to study the effect of iron under natural conditions. Samples of approximately $5 \ell$ water were collected monthly from April through January from each sampling point in chemically clean plastic bottles by Rand Water who also 


\begin{tabular}{|l|c|c|c|}
\hline \multicolumn{4}{|c|}{ TABLE 1 } \\
\multicolumn{4}{|c|}{ Survival of $\begin{array}{l}\text { V. cholerae in 12 industrially polluted } \\
\text { water samples (n=96) }\end{array}$} \\
\hline \multirow{3}{*}{$\begin{array}{c}\text { Month } \\
\text { (1989-90) }\end{array}$} & Survival of V. cholerae in days (n = 7 - 12) \\
\cline { 2 - 4 } & non-01 & El Tor & classical \\
\cline { 2 - 4 } & Mean \pm SE** & Mean \pm SE** & Mean \pm SE$^{* *}$ \\
\hline April & $9.4 \pm 3.3$ & $9.2 \pm 3.4$ & $6.3 \pm 2.0$ \\
May & $7.5 \pm 0.9 *$ & $7.6 \pm 2.6$ & $5.0 \pm 0.8 *$ \\
June & $23.4 \pm 6.4$ & $11.1 \pm 5.5$ & $15.0 \pm 4.5$ \\
July & $28.6 \pm 8.5$ & $6.5 \pm 2.2$ & $18.0 \pm 5.7$ \\
August & $29.4 \pm 4.3$ & $21.7 \pm 6.5$ & $25.7 \pm 5.0$ \\
September & $33.4 \pm 4.4$ & $17.9 \pm 3.8$ & $27.6 \pm 4.7 *$ \\
October & $39.1 \pm 5.7 *$ & $35.1 \pm 5.1 *$ & $26.1 \pm 4.0 *$ \\
November & $24.2 \pm 4.5$ & $23.6 \pm 5.2$ & $18.7 \pm 3.9$ \\
December & $21.6 \pm 5.2$ & $15.3 \pm 3.1$ & $11.5 \pm 2.5$ \\
January & $20.9 \pm 4.2$ & $19.5 \pm 5.6$ & $12.7 \pm 3.0$ \\
\hline * p = <0.05 & \multicolumn{3}{|}{} \\
** Standard error
\end{tabular}

measured their $\mathrm{pH}$ and total iron levels as part of its routine monitoring program. Chemical analyses were done by means of an inductively coupled plasma method. Samples were refrigerated after collection and transported in insulated boxes to our laboratory. On arrival the samples were autoclaved at $121^{\circ} \mathrm{C}$ for $20 \mathrm{~min}$. After cooling to room temperature, the $\mathrm{pH}$ and iron levels were measured again. One litre of water from each sample was transferred into each of three sterile $1 \ell$ glass beakers, which were covered with sterile glass petri dishes. The beakers were inoculated with $V$. cholerae strains. Aseptic precautions were taken during various procedures. The samples were monitored for extraneous bacterial contaminants and, if found to be contaminated, they were excluded from the study.

\section{Bacterial cultures and inocula}

One strain each of two biotypes of $V$. cholerae O1, namely El Tor (National Health Laboratory Service, Johannesburg, South Africa) and classical (Centre of Applied Microbiology and Research at Porton Down, Salisburg, UK), and a strain of $V$. cholerae non-O1 (National Health Laboratory Service) were used in this study. The cultures were maintained in semi-solid agar. During the course of the study, appropriate tests were periodically performed to reconfirm the identity of the cultures prior to their inoculation into water samples. Before experiments, serial subcultures were performed onto fresh blood agar and incubated at $37^{\circ} \mathrm{C}$ for $24 \mathrm{~h}$. A loopful ( $2 \mathrm{~mm}$ diameter) of culture from these plates was inoculated into McCartney bottles containing $10 \mathrm{~m} \ell$ alkaline peptone water(APW) which were then incubated for $16 \mathrm{~h}$ at $37^{\circ} \mathrm{C}$. The inoculum was prepared in this manner for all the experiments. Baseline counts of $V$. cholerae, performed on the inoculum immediately prior to inoculation of water samples, consistently ranged from $10^{8}$ to $10^{9}$ organisms $/ \mathrm{m} \ell$.

\section{Inoculation of water samples and determination of $V$. cholerae survival}

For each water sample, $3 \times 1 \ell$ beakers were inoculated with $0.25 \mathrm{~m} \ell$ V. cholerae non-O1, El Tor and classical respectively. The carry-over effect of APW was largely diluted out and duly mini- mally affected the final $\mathrm{pH}$ in the beakers (data not shown). All inoculated beakers were kept at room temperature. Every day, approximately $4 \mathrm{~m} \ell$ of the inoculated water was removed from each beaker and enriched by overnight incubation in APW and then subcultured on blood agar at $37^{\circ} \mathrm{C}$ for a further $24 \mathrm{~h}$. The results were denoted as a presence or absence of $V$. cholerae. Samples were discarded after three consecutive negative results.

\section{Statistical analyses}

Analyses of the duration of survival were performed by means of the 1-way analysis of variance (ANOVA). The objective was to establish whether there was a significant survival difference between months and strain of $V$. cholerae, and to establish the significance of the effect of $\mathrm{pH}$ and iron, if any, on the duration of survival.

\section{Results}

Of the 120 samples collected over a 10-month period, 24 were excluded from analysis because of contamination, specimens lost during transport or due to laboratory accidents or the individual sampling points yielded too few data (4 to 10 sets of results per sample) for meaningful analyses to be done. For the assessment of seasonal variation in survival, data from the 12 sampling points were pooled, yielding a total of 96 sets of results for each $V$. cholerae strain.

All three $V$. cholerae strains survived longest at ambient temperature in those samples that were collected and inoculated during September (classical) and October (non-O1, El Tor and classical) which, in the Southern Hemisphere, coincides with midspring $(\mathrm{p}=<0.05)$. Survival of $V$. cholerae non-O1 and classical strain was shortest in May (Table 1).

The mean survival time of non-O1 $V$. cholerae was $24 \mathrm{~d}$ which was significantly longer than those of the El Tor and classical strains, both of which were $17 \mathrm{~d}(\mathrm{p}=0.006$ and 0.001 respectively). To evaluate the effect of $\mathrm{pH}$, pooled survival data involving the three $V$. cholerae sero-/biotypes were sorted in order of increasing $\mathrm{pH}$ values and then batched into 12 groups of 8 values each. The 12 survival means, calculated and plotted against the $\mathrm{pH}$ means (Fig.1) show a saddle-back type of curve with a peak at $\mathrm{pH} 7.1$ to 7.4 and a second peak at $\mathrm{pH}>8$. Also inserted on this graph were the mean iron concentrations for each batch showing that the second survival peak coincides with the presence of increased iron concentrations.

These findings, suggesting a possible association between high iron levels and prolonged $V$. cholerae survival at higher $\mathrm{pH}$, stimulated further analysis of $V$. cholerae survival. Data of the 48 samples with the highest $\mathrm{pH}$ values (7.7 to 9.2) were ranked according to increasing iron concentrations into 6 groups of 8 samples each (for each $V$. cholerae strain). Four of these groups (A to D) had comparable mean $\mathrm{pH}$ values ranging from 8 to 8.1 (Table 2), two of which had relatively low mean iron levels (Groups $\mathrm{A}$ and $\mathrm{B}$ ) and the other two had relatively high iron levels (Groups $\mathrm{C}$ and $\mathrm{D}$ ). Groups $\mathrm{E}$ and $\mathrm{F}$ had relatively high $\mathrm{pH}$ values and were therefore excluded from the statistical analysis.

All three cholera strains survived longer in the high iron concentration groups $(\mathrm{C} \& \mathrm{D})$ compared to those with low iron levels (A \& B). This increase in survival was significant in all 4 of the non-O1 comparisons, in 3 out of 4 classical strain comparisons, but in none of the El Tor comparisons (Table 2). The El Tor comparisons show a wide scatter of survival data compared to those of the non-O1 and classical strains. 


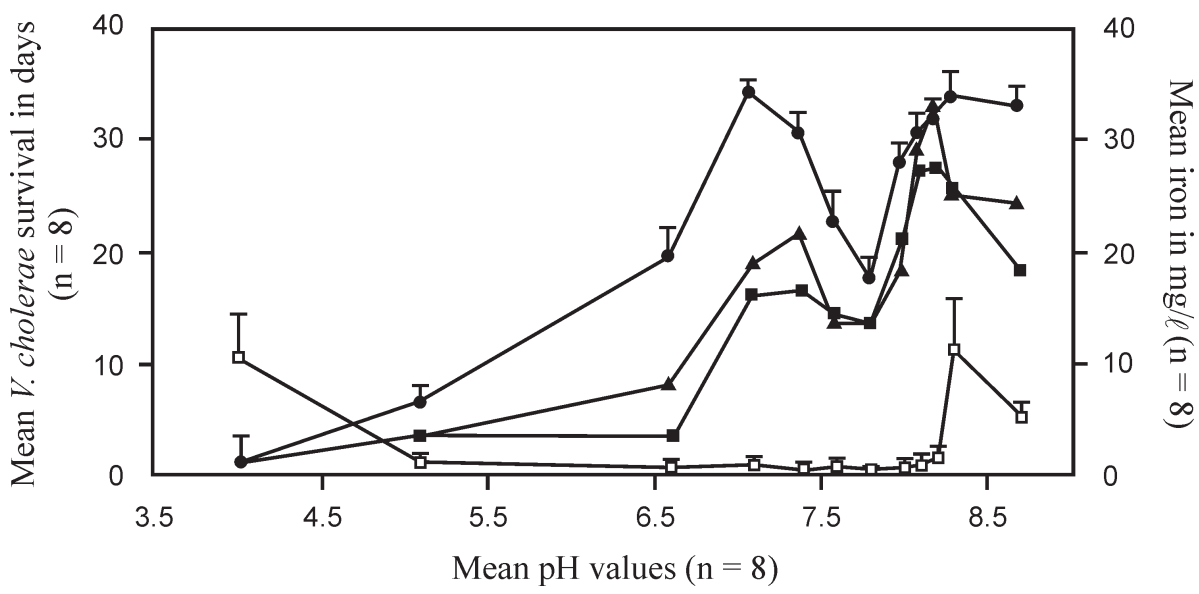

Figure 1

Survival of $\mathrm{V}$. cholerae in the presence of industrial effluent at increasing $\mathrm{pH}$ values. Error bars (SES) of the mean are only given for the $\mathrm{V}$. cholerae non-01.

Other SE values varied

between 0.5 and $7.1 \mathrm{~d}$

(Figures too full to show all SE bars).

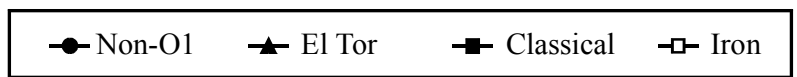

TABLE 2

Distribution of $\mathrm{pH}$ and iron concentration variables of 48 pooled $V$. cholerae survival data used for statistical evaluation by Analysis of Variance (ANOVA)

\begin{tabular}{|c|c|c|c|c|c|c|c|c|}
\hline \multirow[t]{3}{*}{ Group } & \multirow{3}{*}{$\begin{array}{c}\mathrm{pH} \\
\text { mean } \\
\text { (range) }\end{array}$} & \multirow{3}{*}{$\begin{array}{c}\text { Iron } \\
\text { (mg/l) } \\
\text { mean (range) }\end{array}$} & \multicolumn{6}{|c|}{ Survival of $V$. cholerae in days } \\
\hline & & & \multicolumn{2}{|c|}{ non-01 } & \multicolumn{2}{|c|}{ El Tor } & \multicolumn{2}{|c|}{ classical } \\
\hline & & & $\begin{array}{c}\text { Mean } \\
\pm \text { SE(range) }\end{array}$ & $\begin{array}{c}\text { Group } \\
\text { comparison } \\
\text { and } p \text { values }\end{array}$ & $\begin{array}{c}\text { Mean } \pm \text { SE } \\
\text { (range) }\end{array}$ & $\begin{array}{c}\text { Group } \\
\text { comparison } \\
\text { and } p \text { values }\end{array}$ & $\begin{array}{l}\text { Mean } \pm \text { SE } \\
\quad \text { (range) }\end{array}$ & $\begin{array}{c}\text { Group } \\
\text { comparison } \\
\text { and } p \text { values }\end{array}$ \\
\hline A & $8.0(7.7-8.3)$ & $0.04(0.03-0.06)$ & $16.8 \pm 2.3(9-27)$ & & $15.6 \pm 4.2(5-37)$ & & $15.8 \pm 4.4(4-36)$ & \\
\hline & & & & A vs $C:<0.05$ & & A vs $C:>0.05$ & & A vs $C:<\mathbf{0 . 0 5}$ \\
\hline $\mathrm{B}$ & $8.0(7.7-8.1)$ & $0.17(0.07-0.27)$ & $16.4 \pm 2.9(7-28)$ & $\begin{array}{l}A \text { vs } D:<0.05 \\
B \text { v } C:<0.05\end{array}$ & $14.1 \pm 3.4(3-29)$ & $\begin{array}{l}A \text { v v } D: \\
B \text { vs } C:>0.05 \\
\end{array}$ & $13.3 \pm 3.3(5-27)$ & $\begin{array}{l}\text { A vs } D:>0.05 \\
B \text { vs } C \cdot<0.05\end{array}$ \\
\hline $\mathrm{C}$ & $8.0(7.7-8.2)$ & $0.52(0.27-0.95)$ & $36.6 \pm 3.8(17-54)$ & $\mathrm{B}$ vs $\mathrm{D}:<\mathbf{0 . 0 5}$ & $33.5 \pm 7.3(1-57)$ & B vs D: $>0.05$ & $32.4 \pm 3.9(15-47)$ & B vs D: $<\mathbf{0 . 0 5}$ \\
\hline $\mathrm{D}$ & $8.1(8.0-8.3)$ & $1.07(0.96-1.30)$ & $36.0 \pm 6.3(21-76)$ & & $26.1 \pm 6.2(1-54)$ & & $27.6 \pm 4.8(14-47)$ & \\
\hline $\mathrm{E}$ & $8.5(8.0-9.2)$ & $2.70(1.50-3.90)$ & $38.4 \pm 4.1(19-54)$ & $\mathrm{N} / \mathrm{D}$ & $23.3 \pm 6.6(0.5-56)$ & $\mathrm{N} / \mathrm{D}$ & $20.8 \pm 3.5(0.5-29)$ & $\mathrm{N} / \mathrm{D}$ \\
\hline $\mathrm{F}$ & $8.4(8.2-8.7)$ & $14.20(4.90-33.0)$ & $29.4 \pm 3.6(18-45)$ & $\mathrm{N} / \mathrm{D}$ & $29.5 \pm 4.0(14-49)$ & $\mathrm{N} / \mathrm{D}$ & $23.4 \pm 2.4(13-34)$ & $\mathrm{N} / \mathrm{D}$ \\
\hline
\end{tabular}

\section{Discussion}

All three strains of $V$. cholerae (non-O1, El Tor and classical) survived the longest in the month of October (mean number of days 39,35 and 26 respectively), which is the beginning of summer in the Southern Hemisphere. During that time period the temperatures are around $22^{\circ} \mathrm{C}$ to $28^{\circ} \mathrm{C}$. V. cholerae is known to survive for 1 to $20 \mathrm{~d}$ in raw well-water at $20^{\circ} \mathrm{C}$ to $30^{\circ} \mathrm{C}$, although reports from India (Pandit et al., 1967) and Tanzania (Lema et al., 1979) have suggested survival of the El Tor biotypes in raw well-water for over $50 \mathrm{~d}$. The shortest survival period was in the month of May, which is the beginning of winter. The temperatures are around $15^{\circ} \mathrm{C}$ to $19^{\circ} \mathrm{C}$ during this time period. In dechlorinated tap water as well as in raw well-water $V$. cholerae survived up to one month at $4^{\circ} \mathrm{C}$ (Feachem et al., 1981). It seems that very cold and suboptimum growth temperatures $\left(20\right.$ to $\left.30^{\circ} \mathrm{C}\right)$ are better for the survival of V. cholerae. Survival can be appreciably longer in nutrient-rich waters, which have been boiled or autoclaved before contamination by $V$. choleare (Hood and Ness, 1982). This phenomenon was also observed in our study. The longest survival period of
V. cholerae non-O1 was $76 \mathrm{~d}$, El Tor $52 \mathrm{~d}$ and classical $47 \mathrm{~d}$.

$V$. cholerae non-O1 survived significantly longer than El Tor and classical strains. Khan and Agarwal (1929) found non-O1 surviving for longer than classical. The finding in recent years that the non-O1 V. cholerae (O139) Bengal strain can cause epidemic cholera, lends new significance to this survival characteristic.

Our previous findings on enhanced $V$. cholerae survival in defined clean conditions were especially relevant to installed water supplies accessed by pumps and/or conveyed by older type of distribution systems in which iron is a component that, when corrosion takes place, results in increased ferric oxide levels in the water (Patel and Isaäcson, 1995).

In the present report we record the effect of iron on the survival of $V$. cholerae in industrially polluted water. The findings lend further credence to the possibility, suggested by our previous studies, that the survival of $V$. cholerae may be enhanced by raised iron levels resulting from industrial pollution of natural surface waters. This effect is noted only at higher $\mathrm{pH}$. We previously reported the effects of iron on cholera toxin (CT) production in water (Patel and Isaäcson, 1999). For a better understanding of the 


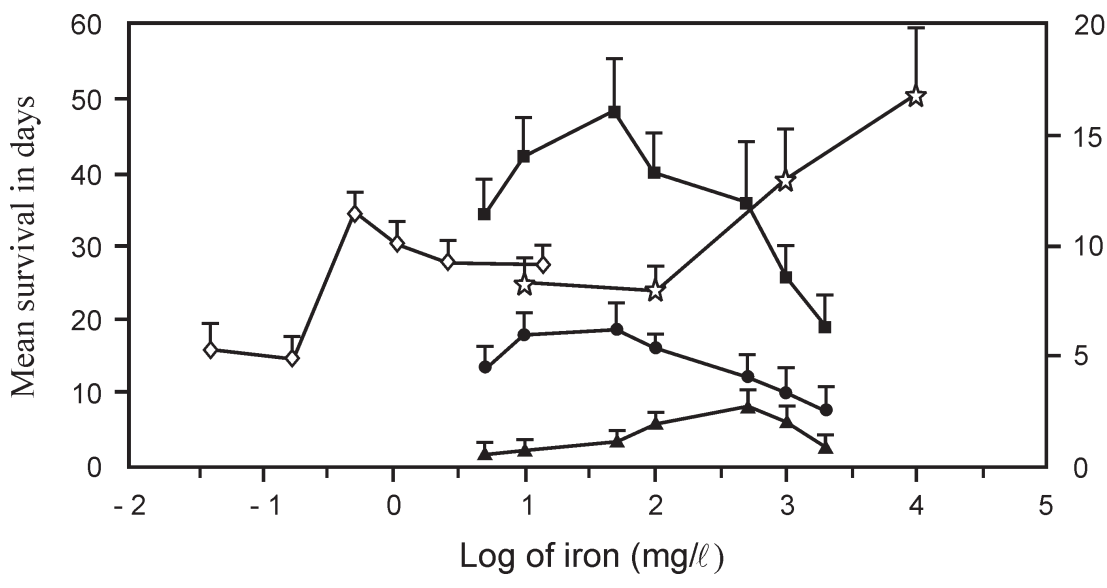

Polluted water study (present study): $\prec-\mathrm{pH} 8-8.5$ Clean water study (Patel and Isaäcson, 1995): $\_$pH7 $\rightarrow \mathrm{pH} 9 \rightarrow \mathrm{pH} 11$

Toxin levels (Patel and Isaäcson, 1999):
Figure 2

The effect of iron on the survival and toxin production of V. cholerae. Bars represent standard errors. possible relationship between iron and $\mathrm{pH}$ in the aquatic environment and on the survival as well as virulence of $V$. cholerae, a composite chart showing the essence of our current and previously published findings is presented in Fig.2. Since the patterns of behaviour by the different $V$. cholerae strains (non-O1, El Tor and classical) had been shown to be similar, their results were pooled for this purpose.

The chart shows that, at a $\mathrm{pH}$ of 8 to 8.5 and iron levels of 0.1 to $10 \mathrm{mg} / \ell$, the survival of $V$. cholerae in polluted water was generally longer than in distilled water at a higher $\mathrm{pH}$ ( 7 to 9$)$ and iron concentrations of $10 \mathrm{mg} / \ell$. This was probably due to the presence of various other nutrients in the polluted surface water samples. In both types of water, over a wide range of $\mathrm{pH}$ values, there seem to be optimal iron concentrations, above which the metal no longer stimulates, and perhaps even inhibits the survival of $V$. cholerae. Our finding that at $\mathrm{pH} 8$ to 8.5 , optimal survival enhancement of $V$. cholerae occurred at iron concentrations of 1 to $10 \mathrm{mg} / \ell$, has important implications. Fifty percent of our samples fall in this category (Fig.1).

There is ample evidence that $V$. cholerae is an autochthonous flora of some estuarine environments (Baker et al., 1983; Colwell et al., 1981; Kaysner et al., 1987; Tison et al., 1986; Miller et al., 1984; Hood et al., 1981; Kaper et al., 1979). Other workers found $V$. cholerae to be indigenous also in freshwater bodies in England (Lee et al., 1982), Japan (Osaka City, 1983) and Germany (Bockemühl et al., 1986). Many factors affect the survival and growth of $V$. cholerae in such environments, such as zooplankton (Kaysner et al., 1990; Nalin et al., 1979; Tamplin et al., 1990), phytoplankton (Spira et al., 1981; Islam et al., 1990a) and algae (Islam et al., 1990b). We suggest that chemical contamination of water may be one of the important factors instrumental in the subsequent ability of $V$. cholerae to persist, multiply and survive in the aquatic environment.

Since polluted water is a common and often the sole source of drinking water for vast rural populations, the potential implications of industrial pollution have here been shown to range far beyond the latter's well recognised association with chronic diseases such as malignancies, cardiac disease, toxic hepatic disease etc (Laurent et al., 1993; McDuffie et al., 2001; Kayajanian GM, 2000; Steenland et al., 1999). In contrast, our studies show the presence of iron in the aquatic environment to be capable of creating conditions, which mediate acute infections and result in the occurrence of epidemic infectious disease.

It has recently been shown that the filamentous phage CTXF which encodes cholera toxin can lysogenise $V$. cholera (Waldor and Mekalanos, 1996) as well as an environmental strain of Vibrio mimicus recovered from surface waters in Bangladesh, converting it into a toxigenic strain (Faruque et al., 1999). This finding suggests that CТХ $\Phi$ could be propagated in Vibrio species other than $V$. cholerae in natural waters. The same group of authors also showed that sunlight induces propagation of this toxin-encoding lysogenic phage and that this may constitute a natural mechanism for the origination of new toxigenic strains of $V$. cholerae (Faruque et al., 2000). Interestingly, СТXФ survives well over a $\mathrm{pH}$ range of 7.0 to 9.5 and exhibits maximal stability at $\mathrm{pH} 8$ to 9 . One third of our samples had a $\mathrm{pH}$ of between 8 and 9 .

Jiang et al. (2000) have shown that although a single clone of pathogenic $V$. cholerae appears responsible for many cases of cholera in Asia, Africa and Latin America during the seventh pandemic, other cases of clinical cholera were caused by toxigenic $V$. cholerae strains that appear to have been derived locally from environmental O1 or non-O1 strains. Environmental pollutants creating suitable conditions for Vibrio survival, as was shown in the present study, could have facilitated this process.

\section{Conclusions}

Natural water bodies are often polluted by industrial effluents due to direct discharge of untreated effluents, leaching of stored industrial sludge and various pollutants of the soil via leaching. Since polluted water is a common and often the sole source of drinking water for vast rural populations, the direct and indirect effect of pollution on this population needs research. The direct effect such as renal and hepatic diseases and cancers have been extensively studied. The indirect effect via disease-causing micro-organisms needs attention. We have shown that cholera-causing bacilli can survive well at high $\mathrm{pH}$ in the presence of specific iron concentrations. Previously we have shown that at high iron concentrations, $V$. cholerae can become more virulent. It is possible that waterborne diseases caused by micro-organisms other than cholera 
bacilli, may also be affected by chemical pollutants.

\section{Acknowledgements}

This work was supported by a grant from the National Health Laboratory Services, South Africa and constitutes part of a thesis by M. Patel, who was awarded a Ph.D. degree by the University of The Witwatersrand. Thanks are due to Rand Water, Vereeniging, South Africa for collecting and supplying water samples as well as making past results available.

\section{References}

BAKER RM, SINGLETON FL and HOOD MA (1983) Effects of nutrient deprivation on V. cholerae. Appl. Environ. Microbiol. 46 930-940.

BOCKEMÜHL J, ROCH K, WOHLERS B, ALEKSIC V, ALEKSIC S and WOKATSCH R (1986) Seasonal distribution of facultatively enteropathogenic vibrios ( $V$. cholerae, $V$. mimicus, $V$. parahaemolyticus) in fresh water of the Elbe river at Hamburg. J. Appl. Bacteriol. 60 435442.

COLWELL RR, SEIDLER RJ, KAPER J et al (1981) Occurrence of $V$. cholerae serotype $\mathrm{O} 1$ in Maryland and Louisiana estuaries. Appl. Environ. Microbiol. 4 555-558.

DWAF (Department of Water Affairs and Forestry) (1996) South African Water Quality Guidelines, Volume 1, Domestic Use (2 ${ }^{\text {nd }}$ edn.) $101 \mathrm{pp}$.

FARUQUE SM, MOSTAFIZUR REHMAN M, ASADULGHANI, NASIRUL ISLAM KM and MEKALANOS JJ (1999) Lysogenic conversion of environmental Vibrio mimicus strains by CTXФ. Infect. Immun. 67 (11) 5723- 5729.

FARUQUE SM, ASADULGHANI, MOSTAFIZUR REHMAN M, WALDOR MK and SACK DA (2000) Sunlight-induced propagation of the lysogenic phage encoding Cholera toxin. Infect. Immun. $\mathbf{6 8}(8)$ 4795- 4801.

FEACHEM RG, MILLER CJ and DRASAR BS (1981) Environmental aspects of cholera epidemiology. II. Occurrence and survival of V. cholerae in the environment. Trop. Dis. Bull. 78 865-880.

FORD WE and DANA ES (1963) A Textbook of Mineralogy (4 $4^{\text {th }}$ edn.), John Wiley and Sons Inc., New York. 485 pp.

HOOD MA, NESS GE and RODRICK GE (1981) Isolation of $V$. cholerae serotype $\mathrm{O} 1$ from the Eastern oyster Crassostrea virginica. Appl. Environ. Microbiol. 41 559-560.

HOOD MA and NESS GE (1982) Survival of $V$. cholerae and Escherichia coli in estuarine waters and sediments. Appl. Environ. Microbiol. 43 578-584.

ISLAM MS, DRASAR BS and BRADLEY DJ (1990a) Survival of toxigenic Vibrio cholerae $\mathrm{O} 1$ with a common duckweed, Lemma minor, in artificial aquatic ecosystems. Trans. R. Soc. Trop. Med. Hyg. 84 422-424.

ISLAM MS, DRASAR BS and BRADLEY DJ (1990b) Long term persistence of toxigenic Vibrio cholerae $\mathrm{O} 1$ in the mucilaginous sheath of a blue-green alga Anabaena variabilis. J. Trop. Med. Hyg. 93 133-139.

JIANG SC, MATTE M, MATTE G, HUQ A and COLWELL RR (2000) Genetic diversity of clinical and environmental isolates of Vibrio cholerae determined by amplified fragment length Polymorphism finger printing. Appl. Environ. Microbiol. 66 148- 153.

KAPER J, LOCKMAN H, COLWELL RR and JOSEPH SW (1979) Ecology, serology and enterotoxin production of $V$. cholerae in Chesapeake Bay. Appl. Environ. Microbiol. 37 91-103.

KAYAJANIAN GM (2000) Arsenic, dioxin, and the promotional step in cancer creation. Ecotoxicol. Environ. Saf. Mar. 45 (3) 195-7.
KAYSNER CA, ABEYTA JR C, WELKELL MM, DEPAOLA JR A, STOTT RF and LEITCH JM (1987) Incidence of Vibrio cholerae from estuaries of the United States west coast. Appl. Environ. Microbiol. 53 1344-1348.

KAYSNER CA, ABEYTA JrC, STOTT RF, KRANE MH and WELKELL MM (1990) Enumeration of Vibrio species including V. choleare, from samples of an oyster growing area, Grays Harbor, Washington. J. Food Protect. 53 300-301.

KHAN S and AGARWAL MN (1929) On the duration of the litre of vibrios in the Ganges and Jumna river water. Indian J. Med. Res. 16993-1008.

LAURENT C, LAKHANISKY T, JADOT P, JORIS I, OTTOGALI M, PLANARD C, BAZZONI D, FOIDART JM and ROS Y (1993) Increased sister chromatid exchange frequencies observed in a cohort of inhabitants of a village located at the boundry of an industrial dumping ground: Phase I. Cancer Epidemiol. Biomarkers Prev. 2 355-362.

LEE JV, BASHFORD DJ, DONOVAN TJ, FURNISS AL and WEST PA (1982) The incidence of Vibrio cholerae in water, animals and birds in Kent, England. J. Appl. Bacteriol. 52 281-291.

LEMA O, OGWA M and MHALU FS (1979) Survival of El Tor cholera vibrios in local water sources and beverages in Tanzania. E. Afr. Med. J. 56 504-508.

McDUFFIEHH, PAHWA P, McLAUGHLIN JR, SPINELLIJJ, FINCHAM S, DOSMAN JA, ROBSON D, SKINNIDER LF and CHOI NW (2001) Non-Hodgkin's lymphoma and specific pesticide exposures in men: Cross-Canada study of pesticides and health. Cancer Epidemiol. Biomarkers Prev. Nov 10 (11) 1155.

MILLER CJ, DRASAR BS and FEACHEM RG (1984) Response of toxigenic Vibrio cholerae $\mathrm{O} 1$ to physico-chemical stresses in 11 aquatic environments. J. Hyg. Camb. 93 475-495.

NALIN DR, DAYA V and REID A (1979) Adsorption and growth of $V$. cholerae on chitin. Infect. Immun. 25 768-770.

OSAKA CITY INSTITUTE OF PUBLIC HEALTH AND ENVIRONMENTAL SCIENCE (1983) Isolation of $V$. cholerae El Tor Inaba from rivers in Osaka city. Ann. Rep. Osaka City Inst. Public Health Environ. Sci. 45 (suppl) 130.

PANDIT CG, PAL SC, MURTI GVS, MISRA BS, MURTY DK and SHRIVASTAV JB (1967) Survival of V.cholerae biotype El Tor in well water. Bull. Wld. Hlth. Org. 37 681-685.

PATEL M and ISAÄCSON M (1995) The effect of $\mathrm{pH}$ and iron on the survival of V. cholerae. Trans. R. Soc. Trop. Med. Hyg. 89 175-77.

PATEL M and ISAÄCSON M (1999) The effect of iron on the toxigenicity of V. cholerae. Am. J. Trop. Med. Hyg. 60 392-396.

RAND WATER BOARD (1987) Analysis of water streams in the catchment areas of the Vaal Dam and the river barrage. RWB $37^{\text {th }}$ Report, pp 1-70. Published by RWB, Johannesburg, South Africa.

SPIRA WM, HUQ A, AHMED QS and SAEED YA (1981) Uptake of $V$. cholerae biotype El Tor from contaminated water by water hyacinth (Eichhornia crassipes). Appl. Environ. Microbiol. 42 550-553.

STEENLAND K, PIACITELLI L, DEDDENS J, FINGERHUT M and CHANG LI (1999) Cancer, heart disease, and diabetes in workers exposed to 2,3,7,8-tetrachlorodibenzo-p-dioxin. J. Natl. Cancer. Inst. May 591 (9) 779-86.

TAMPLIN ML, GAUZENS AL, HUQ A, SACK DA and COLWELL RR (1990) Attachment of Vibrio cholerae serogroup O1 to zooplankton and phytoplankton of Bangladesh waters. Appl. Environ. Microbiol. 56 1977-1980.

TISON DL, NISHIBUCHI M, SEIDLER RJ and SIEBELING RJ (1986) Isolation of non-O1 Vibrio cholerae serovars from Oregon coastal environments. Appl. Environ. Microbiol. 51 444-445.

WALDOR MK and MEKALANOS JJ (1996) Lysogenic conversion by a filamentous phage encoding Cholera toxin. Sci. 272 1910-1914. 
